\title{
Use of titania powders in the laser sintering process: link between process conditions and product mechanical properties
}

\author{
Daniele Sofia $^{a}$, Domenico Macrì ${ }^{b}$, Diego Barletta ${ }^{a}$, Paola Lettieri ${ }^{b}$, Massimo Poletto ${ }^{a}$ \\ ${ }^{a}$ Dipartimento di Ingegneria Industriale, Università di Salerno, Via Giovanni Paolo II, 132, 84084 Fisciano (SA), Italy \\ ${ }^{b}$ Department of Chemical Engineering, University College London, London WC1E 7JE, UK
}

\begin{abstract}
Selective Laser Sintering (SLS) of Titania powders is studied to understand how the initial material properties and the process conditions affect the degre. of sintering/melting and the mechanical properties of the semi-3D artefact produced.Fivf sat ples with differing particle size were used to explore the feasibility of processing th $2 \mathrm{~m}$ y SLS. Laser power and scan

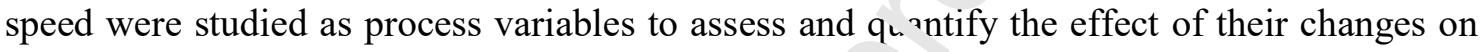
the properties of product. The measured tensile stı.ngt I was used in the equation for the strength of the powder's agglomerates develope: by Rumpf, which allowed estimating the size of the sintered necks. The sintering temp ra $\ldots$ of each powder sample was determined experimentally and used to predict the $\mathrm{s}^{i} \mathrm{e} \mathrm{c}_{i}$ the sintered neck for the different powder grain size using different literature models; $^{1}$ thes values were then compared with the values obtained from the experiments.
\end{abstract}

\section{Keywords}

Selective laser sintering; titanı. powders; particle size distribution; mechanical properties; particle sintering model.

\section{Introduction}

In recent years, technologies related to additive manufacturing are affecting the production processes in many sectors, ranging from dental braces to astronauts' seats [1-4]. Selective laser sintering (SLS) was patented by Carl Deckard [5] in the late-1980s at the University of Texas, and can be considered as one of the first additive manufacturing techniques invented. One of the main advantages of this technique is its versatility to work with multiple granular materials, with different chemical composition and mechanical properties. Among these materials, we can enumerate polymers[6,7], metals, glass, ceramics, and composites [8-17]. Selective laser sintering is classified as one of the "powder bed fusion additive manufacturing processes" since it makes use of thermal energy to fuse local areas of a powder bed 
selectively. In this process, a laser beam is used to create complex $3 \mathrm{D}$ objects with excellent mechanical properties, properties in terms of hardness, toughness, wear resistance, and chemical stability, which can be regulated by using powders of different compositions and other process parameter[18]. Such artefacts are created by subsequent alternating steps of spreading of powder layers[19,20] and steps of selective laser sintering [21].

The interest from the industrial point of view is related to the possibility of rapidly obtaining a prototype of the artefact and be able to produce high temperature resistant components, piezoelectric sensors and actuators, and biocompatible applications in the medical.

SLS owes its popularity to the relatively low cost per part, the high productivity, the reduced energy consumptions and the broad range of manufacturable man rials.

Several papers [22-24] aimed at studying the link betwee $m$ zroscopic properties at the particle scale $[25,26]$ and bulk properties [24] at the $\mathrm{m}$ sosi ale of the powder in bulk by means of complex characterisation of particle properties. 1 more practical approach is based on the direct measurement of powder flow properties.

Contrary to the established laser sintering of 1 etals and plastics, the use for ceramic compounds is still challenging. The diffic lty in controlling the process at the high temperatures required for the sintering \& $f$ tr ese materials generates critical problems such as low density; brittleness; surface irres larities of the objects produced [27]. One of the main reasons identified behind the artefar $\ldots \ldots$ gility lies in the high intensity of residual stresses in the 3D structures produced, due ${ }^{0} \mathrm{O}: \mathrm{e}$ nigh-temperature differences between the parts heated by the laser and the cooled regi ns nearby [28].

Object shrinkage is ano' her ritical issue, in particulary the possibility of not controll the shrinkage prevents the $\mathrm{p}$ rfer $t$ adhesion of the different layers and the success of the sintered product [29]. It strongly i 'epends on the material and the geometry of the fabricated part and the operating conditions. However, as reported by Senthilkumaran et al. [30], accurate calibration of the process conditions can compensate the expected shrinkage and in turn, overcome this problem.

Although Kamyabi et al. [31] reported that the traditional techniques of material sintering do not have such disadvantages, selective laser sintering is still preferred because it allows producing objects significantly more sophisticated and more easily customizable [32,33].

As for all the sintering processes, the strength of the solid necks that develop between particles after the solidification of the molten contact zones determines the strength of the artefact [34-36]. Some operating parameters can be tuned to control the strength of the sintered powders [37]. Among them, the most important are the laser features, the scanning 
time and the properties of the powders used, such as particles size distribution and shape [3841].

The mechanical strength of the artefacts can be characterised either by using compression tests when the object produced has a well-defined 3D structure, or by bending tests if singlelayer objects need to be assessed $[42,43]$. All of these are destructive tests [44].

The present work reports the first results on the production of semi three-dimensional artefacts employing selective laser sintering on titania powders. Five samples with the same chemical composition, but different particle size distribution were used, and the effects of the process conditions were systematically investigated. The internal morphology and mechanical properties of the semi-3D artefacts were analysci using a scanning electron microscopy and a flexural bending test, respectively. Also, $\mathrm{t}$ vo $\mathrm{f}$ lodelling approaches based on the theories of Frenkel[45] and Pokluda et al.[46] arc prc posed in order to evaluate the necks formation and size evolution by considering the vaiations of both the mechanical and the thermophysical properties of the materials during i: a aser sintering process.

The underlying idea is that a good com'rt sension of the fundamental phenomena affecting the sintering process of ceramic $m_{i}$ terials is indispensable for a proper design of such process. To this end, it is imperai ve oo understand the link between the macroscopic properties of the sintered part and the microscopic interparticle necks, in particular, this study of sintered titania will help the ‘relopment of new catalysts among the various applications[47,48].

\section{Materials and Methoa:}

\subsection{Experimental app ara tus}

The experimental se, up has been extensively described by D. Sofia et al. [38]. The laser beam is generated by a $40 \mathrm{~W} \mathrm{CO}$ laser tube with a wavelength of $10.6 \mu \mathrm{m}$. A set of inclined mirrors moving along orthogonal directions allows directing the laser hitting position on the planar powder surface. The whole system generates a laser spot size available is $100 \mu \mathrm{m}$ and allows the tuning of the laser scan velocities between $1 \mathrm{~mm} \mathrm{~s}^{-1}$ and $100 \mathrm{~mm} \mathrm{~s}^{-1}$. The powder materials can be sintered or entirely melted by adjusting the laser power and the laser scan velocity. A 3-D object might be potentially produced by repeating the selective sintering process on overlapped layers of the powder. The two-steps procedure adopted in commercial SLS apparatuses provides a first phase in which the powder sample is lowered to spread a new powder layer on its upper surface. The layer thickness is such that the bed surface is kept 
at the focal plane of the laser beam. In any case, in order to generate the mechanical continuity of the sintered artefact, the thickness of the newly generated layer has to allow the powder sintering thought out its depth. Please note that the experiments reported in this paper are related to sintering on a single layer only.

\subsection{Powder characterisation}

Working samples of powders with narrow particle size distribution (PSD) were obtained by sieving four batches of titania powder $\left(\mathrm{TiO}_{2}\right.$, rutile grade) characterised by a broad particle size distribution and identified as made of particles: 1) $<50 \mu{ }^{\prime}{ }^{\prime}$ 2) between 10 and $100 \mu \mathrm{m}$; 3) between 100 and $200 \mu \mathrm{m}$ and 4) $>200 \mu \mathrm{m}$. The sieved s mp'es were named A to E, and their properties are reported in Table 1. The properties $\mathrm{re}_{\mathrm{r}}$ orted include the particle size identifying the originating batch, the size of the meshe: (undersize and oversize) selected to separate each sample, the mean Sauter diameter $\left(d_{p}\right)$ of th e resulting sample and the sintering temperature $(T s)$.

Particle size distribution was measured wit. a Malvern Mastersizer 2000 based on the light scattering of a laser beam. A hel um pycnometer was used to measure the particle density that resulted in being reasonably su. -ilar to $4300 \mathrm{~kg} \mathrm{~m}^{-3}$ for all the samples. Optical microphotographs of the powder samnlc are reported in Figure 2, where it is possible to observe a certain angularity of the nar ir ie shapes.

A Dielectric Resonator char ibc. (T-Ceram Dielectric Resonator[49]) was used to measure the sintering temperature of ${ }^{\prime} i \gamma_{2}$ powders in combination with a domestic microwave oven ( $\mathrm{P}=1100 \mathrm{~W}$, wavelength oi $1<.2$ centimetres). The chamber has an external diameter of 12 $\mathrm{cm}$, an internal diamel $-018 \mathrm{~cm}$ and a height of $10 \mathrm{~cm}$. This choice was motivated by the complexity of direct temperature measurement in the SLS process, due to the point nature of the heating process. When the Dielectric Resonator chamber is exposed to the microwaves, it quickly reaches a temperature sufficiently high and homogenous to generate the sintering of the sample of ceramic powder hosted inside. The chamber resonating walls are thickly lined with an insulating shell in order to keep the inside temperature after the exposure to microwaves and to avoid the damage of the surfaces externally in contact with the resonating walls. In order to estimate the sintering temperature, the procedure adopted is as follows: first, a sample of powder of $1.0 \mathrm{~g}$ was placed inside the chamber. Repeated heating cycles at increasing microwave exposure times were carried out, for a duration of 10-20 min per cycle. At the end of each cycle, the temperature reached by the powder was measured by 
inserting a $\mathrm{J}$ thermocouple inside the chamber through a hole present on the chamber lid. Afterwards, the chamber was open, and the powder sample inspected for sintering using an optical microscope. The particle sintering temperature was assumed as the lower temperature at which some sintering was visually observed.

\subsection{Sintering procedure}

The selective laser sintering apparatus described above was used to produce squared artefacts $(10 \times 10 \mathrm{~mm})$ made of a single layer of sintered powder. The first step was the generation of consolidated beds of powder. Powder samples were loaded and levelled in cylindrical caps and consolidated using the apparatus descri ed elsewhere [38]. It has a circular lid which allows applying normal vertical stress wh le $\iota$ visting the lid. All samples were consolidated applying normal vertical stress of 7.5 'Pa and two $90^{\circ}$ twists; this procedure allows to obtain surfaces without irregulaı ties, and allows to standardize the procedure for preparing powder beds to be sinterec $\lceil 50]$. The sintering process of squared artefacts was carried out by moving the laser beam along 51 parallel lines with a length of 10 $\mathrm{mm}$ each, the distance between parallel lines $1 \mathrm{ds}=\mathrm{n}$ set to $0.2 \mathrm{~mm}$. The set laser power was $10 \mathrm{~W}$, and the laser scanning speed was ' arif $\mathrm{d}$ between $50 \mathrm{~mm} \mathrm{~s}^{-1}$ and $150 \mathrm{~mm} \mathrm{~s}^{-1}$.

Once the sintering process is concluded, the sintered artefacts were taken out of the bed with the necessary care to avoid $b_{\mu} r^{1} a_{\S} a$ during manipulation. A paintbrush was used to remove any particles loosely $a^{11}-r_{1}-s$ to the artefact. Artefacts were weighed with an analytical balance (300 Crystal.

\subsection{Artefacts characteri ati on}

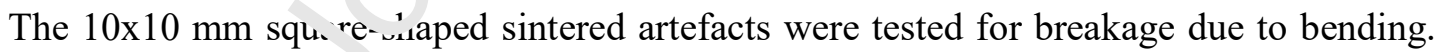
The bending test cc...ists of a standardised three-point bending test. Forces and displacements were measured by an Instron dynamometer (Model 5865) mounting a load cell of $2.5 \mathrm{~N}$ and a specially designed tool that allows testing small size samples. More details are reported in [38].

The force $(F)$ and the deflection $(h)$ of the sample at breakage are used to estimate the tensile strength $\sigma$ of the artefact according to what reported by Richerson [51]:

$$
\sigma=\frac{M_{\mathrm{b}}}{I} \frac{h}{2}=F \frac{3 L}{2 b t^{2}}
$$


where $M_{\mathrm{b}}$ is the applied bending moment, $I$ is the horizontal moment of inertia of a rectangular vertical cross-section geometry, $b$ is the width, $L$ is the distance separating the holder supports and $t$ is the thikness.

In order to examine the microstructures of the final artefacts, they were observed with optical microscopy (Olympus BX51). The actual length of the sintered bridge across the interparticle contact points was measured on the surfaces of the square-shaped sintered artefacts by using the public domain image processing program ImageJ [52].

\section{Experimental results}

A laser beam a scan speed ranging from 5 to $15 \mathrm{~mm} \mathrm{~s}-1$ arce with a power of $10 \mathrm{~W}$ was used to sinter single layer specimen. The products are reporte ${ }^{1}$ in he macroscale photographs of Figure 1 and microscale photographs of Figure 2. Ins1 ecti on of the two figures indicates that both the particle size of the particles and the ${ }^{1}{ }^{9} s_{2}$. scanning speed affect the final morphology and the strength of the final artefacts, as $w ?$ a as the extent of the sintering, or the melting, produced by the laser beam.

The macro photographs of the whole $10 \times 1: \mathrm{mm}$ artefacts are arranged in a tabular form in Figure 1, where each row is associated, itt the mean diameter of the initial powder sample. The first row reports the finest samp'a (case A, $d_{p}=28 \mu \mathrm{m}$ ), and the last row the coarsest sample (case E, $d_{p}=245 \mu \mathrm{m}$ ). Inspe iti ${ }^{\prime}$ ' of such figures confirms that the successful creation of the artefacts, as well as their le. $\bullet$ of shape definition, is strongly affected by both the powder's particle size and the i 'ser scanning speed. In particular, for case A, the geometry of the layers is well defined c lly vhen the laser scanning speed is set to 5 and $10 \mathrm{~mm} \mathrm{~s}^{-1}$; for higher scanning speed, nstrad, the samples appear very brittle and with an unclear final geometry. In the case B $\left(l_{p}=58 \mu \mathrm{m}\right)$, the geometry of the layers is well defined for all laser scanning speeds, but at the highest speed, i.e. $15 \mathrm{~mm} \mathrm{~s}^{-1}$, the artefacts appear more fragile than the others. In the case $\mathrm{C}\left(d_{p}=116 \mu \mathrm{m}\right)$, the geometry of the layers is well defined for laser scanning speeds of 5 and $10 \mathrm{~mm} \mathrm{~s}^{-1}$, while the highest scanning speed employed does not allow any form of artefacts at all. In the last two cases $\left(d_{p}=180-245 \mu \mathrm{m}\right)$, the formation of the artefacts was only possible with a laser scanning speed of $5 \mathrm{~mm} \mathrm{~s}^{-1}$.

The optical microscopic pictures of the front views of the sintered artefacts are reported in Figure 2. They revealed that, for the finer powders (cases A and B), the particles melted entirely throughout the surface leading to final solidified artefacts made out by lumps, with size and shape far different from those of the starting particles. On the other hand, the melting of the coarser particles (cases D and E) was limited to small regions close to the contacts 
between particles. Therefore, the primary particles kept size and shape in the final sintered artefact. For powders with middle-size particles (case C) an intermediate morphology was obtained. Similar observations were reported by Sofia et al. (2018)[38] about selective laser sintering of other ceramic powders, i.e. soda-limestone glass beads and silicon powders [3840].

These results, obtained at fixed scan velocity and power of the laser, highlight that the melting level of the powders is significantly affected by the particle size. The outcome of the bending tests further supports these observations. The results of the tests in term of artefact mass, thickness and tensile strength, are reported in Figure 3 as a function of the initial particles size. Values of the peak force registered during the bєı ${ }^{\text {ing }}$ tests, $F$, are reported as well. During the bending test, the orientation of the artefa $t \mathrm{v}$ as kept similar to the one assumed during the sintering process. Therefore, the ansie strength of the material is representative of the lower side of the artefact, which is $a_{1}$ ? weaker.

Figure 3 shows that both the artefacts weight anc tassile strength decrease dramatically with increasing the particle size when the sam $f$ l ser speed is used. Alternatively, the layer thickness increases with the particle size un $\backsim d_{p}=116 \mu \mathrm{m}$, and it keeps almost unchanged for the largest particle sizes $\left(d_{p}=180-2 \sigma^{5} \mu^{\prime}, \mathrm{n}\right)$. The values of thickness recorded for both the smallest case (A) and the largest ont are the lowest ones, and they are similar to each other (around $0.6 \mathrm{~mm}$ ). The highest value $\mathrm{o}^{+}$. he thickness, $\delta$, is instead observed for the case $\mathrm{C}$. In order to relate the values observ id ' 'r the thickness with the penetration depth of the laser beam, the depth rise and the $i^{\prime}$ eal number of sintered rows, N Row, are also reported. For simplicity, both the parar. ster have been calculated by assuming that the particles are spherical, monodispersec anc tightly packed, following a regular arrangement (see Figure 4):

$$
\begin{gathered}
\text { Depth rise }=\frac{\delta-d_{p}}{d_{p}} \times 100 \\
\text { N Row }=\frac{\delta}{d_{p}}
\end{gathered}
$$

These two parameters decrease with increasing particles size, suggesting that smaller particles promote the penetration of the laser beam: indeed, the number of rows of particles involved in the melting/sintering process, as well as the depth rise, is higher for smaller particles.

The discussion on the image results so far reported and the properties of the sintered artefacts measured suggest that, at the investigated laser power and scanning speeds, the 
transition between melting and sintering processes occurs with the sample B, corresponding to particles of $58 \mu \mathrm{m}$. An almost complete melting is observed with the finest samples (28 and $58 \mu \mathrm{m})$. Such a change in the behaviour of the particles might be attributed to the reduction of the number of particles hit by the laser beam (which has a diameter spot of 100 $\mu \mathrm{m}$ ) with increasing particle size. This might lead to the formation of a weaker sintered bridge across the interparticle contact points, which in turn causes a more fragile final structure of the artefacts.

A fundamental aspect for the sintering process is the phase of formation of the powder bed which needs to be compressed to reduce the porosity of the final sintered products [53-55].

\section{Discussion}

As reported by Franco et al. [56], the development of : $m p$ e phenomenological models is needed to estimate and optimise the SLS process parmes ns testing range as scan velocity 5 to $15 \mathrm{~mm} \mathrm{~s}^{-1}$ and power of the laser 5 to $20 \mathrm{w}$. Thi is mainly necessary because of the complex interaction between transport phenor er a and chemical reactions, as well as the changes of the thermophysical and mechani $a l$ properties of the materials involved in the selective laser sintering process.

Frenkel [57] developed one of the arliest models with the aim to describe the sintering phenomenon, assuming a motion of $\mathrm{h} ;$, lasticized material in the viscous regime:

$$
\left(\frac{d_{n}}{d_{p}^{-}}\right)^{2}=\frac{3 \gamma}{\pi \eta d_{p}} t
$$

According to this mode, the sintering process, represented in terms of the ratio between the neck size $d_{n}$ and the Sa iter diameter $d_{\mathrm{p}}$ as a function of time, depends on the surface tension, $\gamma$, the viscosity of the melted material, $\eta$, the sintering process time, $t$, and the original particle size, $d_{p}$. According to Equation (4), the speed of the sintering process increases with the material surface tension and with decreasing viscosity and particle size. However, one of the assumptions behind the Frenkel's model is that the particle size is not affected by the sintering process which limits the validity of the model to the initial part of the sintering process, in which the neck size is very different from the particle size.

Pokluda et al. [46] modified the model proposed by Frenkel in order to take into account also the effects of geometric and physical arrangements on the coalescence rate. They developed a sintering model based on the balance of the work of surface tension and the viscous dissipation (all the other forces, including gravity, are neglected) which describes the 
complete sintering process of two spherical particles. The shape evolution of the interacting particles develops as shown in Figure 4, and it can be mathematically expressed as follows:

$$
\frac{d_{n}}{d_{p}}=\sin \theta\left(\frac{4}{(1+\cos \theta)^{2}(2-\cos \theta)}\right)^{\frac{1}{3}}
$$

where $\theta$ represents the angle of the intersection of the neck whose evolution with time $t$ can be described according to Eqn. (6).

$$
\frac{d \theta}{d t}=\frac{0.32 \gamma}{d_{p} \eta} \frac{\cos \theta \sin \theta(2-\cos \theta)^{\frac{1}{3}}}{(1-\cos \theta)(1+\cos \theta)^{\frac{1}{3}}}
$$

Both Frenkel and Pokluda models need the surface tensio $\_\gamma$ and the viscosity $\eta$ values estimated at the sintering temperature and, therefore, the corr ${ }^{n+} a_{1}$ plication of these models requires to include the actual temperature dependence of these ". material used in this study, the temperature-dependent $\mathrm{q}_{\mathrm{t}^{\text {nt }}}$ : on for the viscosity (expressed in $\mathrm{cP}$ ) was extrapolated by the measurement run by F'an' 'field and Charette [59] on industrial high $\mathrm{TiO}_{2}$ slags with composition similar to the titar'a u.ed in this work, with low content of impurities:

$$
\eta=42800-7 \text { s.1: } T
$$

The surface tension (expressed in $\mathrm{N} \mathrm{m}^{-1}$ ) $\mathrm{o}^{2}$ the molten phase was evaluated by considering the Hamaker constant of the material, acu rding to the relationship suggested by Israelachvili [60]:

$$
\gamma=\frac{A}{24 \pi D_{0}^{2}}
$$

$D_{0}$ is a "cut off" distan $\_$"hat is substantially less than the interatomic or intermolecular centre-to-centre distan ${ }^{2}$ and the value of $0.165 \mathrm{~nm}$ can be assumed [61,62]. $A$ is the Hamaker constant of the material $\left(1.59 \times 10^{-19} \mathrm{~J}\right.$ as reported by [63]).

Experimental estimates of the neck size were obtained with the use of the Rumpf [64] equation, developed initially to relate the strength of powder agglomerates with the forces acting between particles:

$$
F=\sigma \frac{d_{p}^{2}}{(1-\varepsilon)} \varepsilon
$$

where $\varepsilon$ is the system porosity that can be calculated from the sample mass, $m$ and the thickness $\delta$, provided the horizontal artefact surface, $\Sigma$, and the particle density, $\rho_{p}$ :

$$
\varepsilon=1-\frac{m}{\Sigma \delta \rho_{p}}
$$


The connecting force $\mathrm{F}_{\mathrm{b}}$ is provided by a sintered connection bridge that depends on the titania tensile strength $\sigma$ and the bridge neck size:

$$
d_{\mathrm{n}}=\sqrt{\frac{4 F_{b}}{\sigma \pi}}
$$

Provided the tensile strength reported in Figure 3, equations (9) to (11) allow estimating the experimental size of the connecting bridges, which is reported in Figure 5. The measurement of the tensile strength of the artefact is carried out so that the traction side of the specimen in the three-point bending test coincides with the lower side of the artefact, the weakest because it is the farthest reached by the laser. Therefore, it is likely tha the relevant local temperature is lower than the sintering temperature measured with the pre en $\operatorname{tre}$ explained in section 2.2, whose results are reported in Table 1. Using this tempers'un in equations (4) to (7) allows obtaining model evaluations of the size of the interpart le ${ }^{-1} \mathrm{cks}$, which are also reported in Figure $5(\mathrm{~A})$.

Inspection of the figure confirms that the models' preciictions follow the same trend as the experimental observation, although they overs ${ }^{\circ} \mathrm{m}$ 'te the size of the necks in all the cases investigated. Such a deviation is indicati e $f t_{1} 2$ inadequacy of the two models to take into account other phenomena rather than the effects of the variation of surface tension and viscosity due to the sudden increase nt ' e temperature. As reported by Franco et al. [56], a proper SLS model should reproduce tr.e thermal history within the powder bed when the incident radiation is scanned $\mathrm{o}^{*} \mathrm{t}$. it. Moreover, it should also be considered that not all the released laser energy is used $\sim$ t.elt the material since, in parallel with the melting process, heat dispersion occurs tor, $: y$ uifferent mechanisms of heat transfer [40,65]. Quantification of these effects remains, 1 ' $w_{v}$ er, a task to be accomplished.

The overestimation $\mathrm{vi}$ the models can also be related to the characteristic dimension chosen for the modelling analysis. Both the models are based on the viscous flow under the action of surface tension and, therefore, the true extent of the contact between the sintering particles is crucial. For this reason, the radius of curvature of the contacting particles should be considered as the characteristic dimension of the models rather than the initial radius of the particle.

Figures 5 (B) and 5 (C) show the results of the sensitivity analysis of both Frenkel and Pokluda et al. models with the value of the characteristic length, $d_{p}$. Values of the curvature radius in the range of $30-90 \%$ of the initial size of the particle have been considered. 
The results highlight the critical effect of the curvature radius on the theoretical assessment of sintered neck size. Moreover, the initial size of the particles and the kind of model chosen seem to have a significant influence as well. It can be observed that the model suggested by Frenkel matches with the experimental evidence if small values of curvature radius are considered; the smaller the initial particles, the smaller is the value of the curvature radius required. Pokluda et al. model suggests, instead, an opposite trend: the smaller the particle, the higher is the required curvature radius to fit with the experimental results. It is worth pointing out that both models suggest a perfect match with the experiments for the same values of curvature when the largest particles are considered, namely curvature radii equal to the $50 \%$ and the $60 \%$ for the particles with the initial $\therefore$ ' 'meter of 180 and $245 \mu \mathrm{m}$ respectively.

Therefore, the sensitivity analysis shows that the $m_{1}$ deling approaches here analysed might provide reasonable estimates of the sintered ner ${ }^{1} s_{1_{\Sigma}} \bullet$ if the radius of curvature is taken into account. This calls attention to the need of develı - ing a more accurate model that takes into consideration the complex and deep interac' $1^{-}$, hetween the transport phenomena and the thermophysical variations of the materials $\mathrm{du}_{\mathrm{u}} \mathrm{ng}$ the selective sintering processes induced by the laser.

\section{Conclusions}

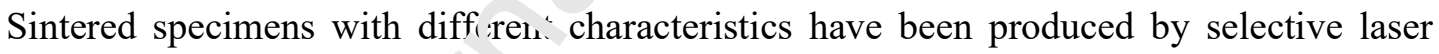
sintering process using a titanı nowder of different size. The variables investigated were the power and the scanning $s_{\mathbf{r}}$ eer of the laser beam. The limiting conditions necessary to produce artefacts with $\mathrm{n}$ inir lum strength (power laser $10 \mathrm{~W}$ and $5 \mathrm{~mm} \mathrm{~s}^{-1}$ as scan velocity) were determined with the help of optical analysis.

A tree point flexural bending test purposely developed allowed to estimate the mechanical properties of the artefacts, precisely the tensile strength. Experiments show that the strength of the artefacts is strongly dependent on the process operating conditions and decreases dramatically with increasing the particles size. The artefacts weight, thickness and tensile strength follow the same trend, suggesting that smaller particles promote the penetration of the laser beam in the bulk of the powder bed and, thus, lead to the formation of more durable bridges across the particle giving a more robust final structure of the artefacts. Moreover, it was observed that specific particle size, i.e. that of sample B $\left(d_{p}=28 \mu \mathrm{m}\right)$, separates the smaller sizes for which melting occurs and the larger sizes for which sintering occurs: indeed, 
the results obtained for the finest samples indicated complete melting of the initial particles, rather than sintering.

Powder sintering temperature was estimated experimentally with a dedicated procedure making use of a dielectric resonator chamber in a microwave oven. The theoretical approaches of Frenkel[45] and Pokluda et al.[46], which are generally used to describe the sintered neck evolution over time, have been employed for modelling the formation of the sintered interparticle bridges. In parallel, the Rumpf equation that relates the strength of agglomerates with interparticle forces was used to estimate the neck size. We observed that the model predictions follow the same trend as the experimental observations. However, they

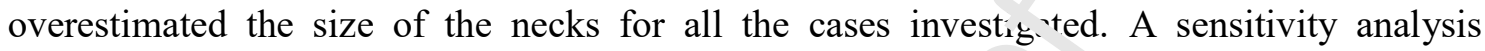
performed on the models' parameters suggests that the d scre pancy between model and experiments can be related to the angular shape of the part cles used in the experiments.

\section{Nomenclature}

\begin{tabular}{|c|c|}
\hline$m$ & mass \\
\hline$\Gamma$ & force \\
\hline$h$ & sample deflection \\
\hline & tensile strength of the artefact \\
\hline$d_{p}$ & particle sizes \\
\hline 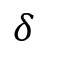 & thickness \\
\hline$d_{n}$ & neck size \\
\hline$\gamma$ & surface tension \\
\hline & viscosity of the melted \\
\hline & sintering process tire \\
\hline & horizontal artefac. su face \\
\hline & particle densi \\
\hline
\end{tabular}

\section{References}

[1] X. Luo, Y. Liu, C. Gu, Z. Li, Study on the progress of solidification, deformation and densification during semi-solid powder rolling, Powder Technol. 261 (2014) 161-169. https://doi.org/10.1016/j.powtec.2014.04.001.

[2] C. Liu, Z. Xia, J.T. Czernuszka, Design and development of three-dimensional scaffolds for tissue engineering, Chem. Eng. Res. Des. 85 (2007) 1051-1064. https://doi.org/10.1205/cherd06196.

[3] L.S. Ojala, P. Uusi-Kyyny, V. Alopaeus, Prototyping a calorimeter mixing cell with direct metal laser sintering, Chem. Eng. Res. Des. 108 (2016) 146-151. https://doi.org/10.1016/j.cherd.2015.11.015.

[4] D.D. Gu, W. Meiners, K. Wissenbach, R. Poprawe, Laser additive manufacturing of metallic components: materials, processes and mechanisms, Int. Mater. Rev. 57 (2012) 
133-164. https://doi.org/10.1179/1743280411Y.0000000014.

[5] C.R. Deckard, Method and apparatus for producing parts by selective sintering, (1989). https://patents.google.com/patent/US4863538.

[6] P. Feng, M. Niu, C. Gao, S. Peng, C. Shuai, A novel two-step sintering for nanohydroxyapatite scaffolds for bone tissue engineering., Sci. Rep. 4 (2014) 5599. https://doi.org/10.1038/srep05599.

[7] C. Shuai, L. Yu, P. Feng, Y. Zhong, Z. Zhao, Z. Chen, W. Yang, Organic montmorillonite produced an interlayer locking effect in a polymer scaffold to enhance interfacial bonding, Mater. Chem. Front. 4 (2020) 2398-2408. https://doi.org/10.1039/d0qm00254b.

[8] P. Bertrand, F. Bayle, C. Combe, P. Goeuriot, I. Smurov, Ceramic components manufacturing by selective laser sintering, Appl. Suri. Sci. 254 (2007) 989-992. https://doi.org/10.1016/j.apsusc.2007.08.085.

[9] M. Agarwala, D. Bourell, J. Beaman, H. Marcus, J Ba low, Direct selective laser sintering of metals, Rapid Prototyp J. 1 (1995) 26-36. https://doi.org/10.1108/13552549510078113.

[10] W.E. Frazier, Metal Additive Manufacturing: ^ k.view, J. Mater. Eng. Perform. 23 (2014) 1917-1928. https://doi.org/10.1007/s1 i 65 014-0958-z.

[11] G.N. Levy, R. Schindel, J.P. Kruth, Rapid Manufacturing and Rapid Tooling With Layer Manufacturing (Lm) Technologie: S ate of the Art and Future Perspectives, CIRP Ann. - Manuf. Technol. 52 (₹103) 589-609. https://doi.org/10.1016/S00078506(07)60206-6.

[12] M. Schmidt, D. Pohle, T. Rechtenwa' 't, Selective laser sintering of PEEK, CIRP Ann. - Manuf. Technol. 56 (2007) 20_-208. https://doi.org/10.1016/j.cirp.2007.05.097.

[13] K.H. Tan, C.K. Chua, K.F. L o g, C.M. Cheah, W.S. Gui, W.S. Tan, F.E. Wiria, Selective laser sintering $\sim^{f}$ urocompatible polymers for applications in tissue

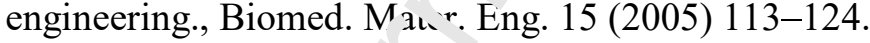

[14] A. Lohner, Laser sint rinc ushers in new route to PM parts, Met. Powder Rep. 52 (1997) 24-30. https: /, 'loi org/10.1016/S0026-0657(97)86910-X.

[15] A. Rosochowski, A. $\perp$ Tatuszak, Rapid tooling: the state of the art, J. Mater. Process. Technol. 106 (2と`) 191-198. https://doi.org/10.1016/S0924-0136(00)00613-0.

[16] X.C. Wang, T. Luoui, J. Bonse, J.P. Kruth, B. Lauwers, L. Froyen, Direct Selective Laser Sintering of Hard Metal Powders: Experimental Study and Simulation, Int. J. Adv. Manuf. Technol. 19 (2002) 351-357. https://doi.org/10.1007/s001700200024.

[17] L. Hongjun, F. Zitian, H. Naiyu, D. Xuanpu, A note on rapid manufacturing process of metallic parts based on SLS plastic prototype, J. Mater. Process. Technol. 142 (2003) 710-713. https://doi.org/10.1016/S0924-0136(03)00811-2.

[18] A. Pilipović, T. Brajlih, I. Drstvenšek, Influence of processing parameters on tensile properties of SLS polymer product, Polymers (Basel). 10 (2018). https://doi.org/10.3390/polym10111208.

[19] M. Ahmed, M. Pasha, W. Nan, M. Ghadiri, A simple method for assessing powder spreadability for additive manufacturing, Powder Technol. 367 (2020) 671-679. https://doi.org/10.1016/j.powtec.2020.04.033.

[20] S. Haeri, Optimisation of blade type spreaders for powder bed preparation in Additive 
Manufacturing using DEM simulations, Powder Technol. 321 (2017) 94-104. https://doi.org/10.1016/j.powtec.2017.08.011.

[21] J.P. Kruth, X. Wang, T. Laoui, L. Froyen, Lasers and materials in selective laser sintering, Assem. Autom. 23 (2003) 357-371. https://doi.org/10.1108/01445150310698652.

[22] H. Shi, R. Mohanty, S. Chakravarty, R. Cabiscol, M. Morgeneyer, H. Zetzener, J.Y. Ooi, A. Kwade, S. Luding, V. Magnanimo, Effect of particle size and cohesion on powder yielding and flow, KONA Powder Part. J. 2018 (2018) 226-250. https://doi.org/10.14356/kona.2018014.

[23] M. Röck, M. Morgeneyer, J. Schwedes, D. Kadau, L. Brendel, D.E. Wolf, Steady state flow of cohesive and non-cohesive powders: IIIInvestigations in experiment and simulation, Granul. Matter. 10 (2008) 285-293. https://doi.org/10.1007/s10035-0080088-0.

[24] M. Röck, M. Morgeneyer, J. Schwedes, L. Bre ılt' D.E. Wolf, D. Kadau, Visualization of shear motions of cohesive powderc tise true biaxial shear tester, Part. Sci. Technol. 26 (2008) 43-54. https://doi.org, 10.1 )80/02726350701759233.

[25] M. Thomas, G.J. Baxter, I. Todd, Normalised n. del-based processing diagrams for additive layer manufacture of engineering alloy , Acta Mater. 108 (2016) 26-35. https://doi.org/10.1016/j.actamat.2016.02.025.

[26] S. Drücker, I. Krautstrunk, M. Paulic к. Y. Saleh, M. Morgeneyer, A. Kwade, Development of an experimental setı $\rho:$ the measurement of the coefficient of

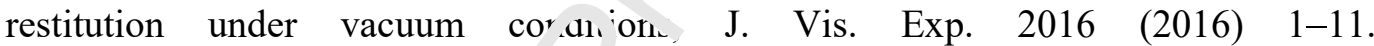
https://doi.org/10.3791/53299.

[27] F. Klocke, C. Ader, Direct lası - sintering of ceramics, Solid Free. Fabr. Symp. (2003) 447-455.

[28] H.-H. Tang, H.-C. Yen, Ceran ii, Parts Fabricated by Ceramic Laser Fusion, Mater. Trans. 45 (2004) 2744-27 1. hitps://doi.org/10.2320/matertrans.45.2744.

[29] L. Benedetti, B. Brulé 1 ' Decreamer, K.E. Evans, O. Ghita, Shrinkage behaviour of semi-crystalline polymer. in laser sintering: PEKK and PA12, Mater. Des. 181 (2019). https://doi.org/10.1 1 h/j.matdes.2019.107906.

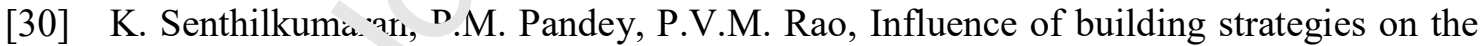
accuracy of parts in selective laser sintering, Mater. Des. 30 (2009) 2946-2954. https://doi.org/10.1016/j.matdes.2009.01.009.

[31] M. Kamyabi, R. Sotudeh-Gharebagh, R. Zarghami, K. Saleh, Principles of viscous sintering in amorphous powders: A critical review, Chem. Eng. Res. Des. 125 (2017) 328-347. https://doi.org/10.1016/j.cherd.2017.06.009.

[32] L. Olmos, C.L. Martin, D. Bouvard, Sintering of mixtures of powders : Experiments and modelling, Powder Technol. $190 \quad$ (2009) 134-140. https://doi.org/10.1016/j.powtec.2008.04.057.

[33] B. Qian, Z. Shen, Laser sintering of ceramics, J. Asian Ceram. Soc. 1 (2013) 315-321. https://doi.org/10.1016/j.jascer.2013.08.004.

[34] A. Ellis, C.J. Noble, N. Hopkinson, High Speed Sintering: Assessing the influence of print density on microstructure and mechanical properties of nylon parts, Addit. Manuf. 1 (2014) 48-51. https://doi.org/10.1016/j.addma.2014.07.003.

[35] J. Seville, U. Tüzün, R. Clift, Processing of Particulate Solids, Springer Netherlands, 
Dordrecht, 1997. https://doi.org/10.1007/978-94-009-1459-9.

[36] D. Macrì, S. Sutcliffe, P. Lettieri, Fluidized bed sintering in $\mathrm{TiO} 2$ and coke systems, Chem. Eng. J. 381 (2020) 122711. https://doi.org/10.1016/j.cej.2019.122711.

[37] C. Luan, C. You, A novel experimental investigation into sintered neck tensile strength of ash at high temperatures, Powder Technol. 269 (2015) 379-384. https://doi.org/10.1016/j.powtec.2014.09.031.

[38] D. Sofia, D. Barletta, P. Massimo, Laser sintering process of ceramic powders: the effect of particle size on the mechanical properties of sintered layers, Addit. Manuf. submitted (2018).

[39] D. Sofia, R. Chirone, P. Lettieri, D. Barletta, M. Poletto, Selective laser sintering of ceramic powders with bimodal particle size distribution, Chem. Eng. Res. Des. 136 (2018) 536-547. https://doi.org/10.1016/j.cherd.2018.06 008.

[40] D. Sofia, M. Granese, D. Barletta, M. Poletto, Laser Sinter. 9 of Unimodal Distributed Glass Powders of Different Size, Procedia Eng 102 (2015) 749-758. https://doi.org/10.1016/j.proeng.2015.01.180.

[41] H. Salehi, D. Sofia, D. Schütz, D. Barletta, M. Pr teı, Experiments and simulation of torque in Anton Paar powder cell, Part. Sc. Technol. 36 (2018) 501-512. https://doi.org/10.1080/02726351.2017.14098 ?

[42] Y. Tang, J.Y.H. Fuh, H.T. Loh, Y.S. Wong, L. Lu, Direct laser sintering of a silica sand, Mater. Des. 24 (2003) 623-629. h t’s: /doi.org/10.1016/S0261-3069(03)001262 .

[43] X. Tian, J. Günster, J. Melcher, I. J.i, J.G. Heinrich, Process parameters analysis of direct laser sintering and post treaı nent of porcelain components using Taguchi's method, J. Eur. C'ram. Soc. 29 (2009) 1903-1915. https://doi.org/10.1016/j.jeurc ثr ‘nsoc.2008.12.002.

[44] F. Xie, X. He, S. Cao, X. Cu, Su uctural and mechanical characteristics of porous 316L stainless steel fabricate 1 hy indirect selective laser sintering, J. Mater. Process. Technol. 213 (2013) 838 843. https://doi.org/10.1016/j.jmatprotec.2012.12.014.

[45] J. Frenkel, Viscous flov' of crystalline bodies under action of surface tension, J. Physics, USSR. 9 , 14.'5) 385.

[46] O. Pokluda, C.'1. Beilehumeur, J. Vlachopoulos, Modification of Frenkel's model for sintering, AIChE I 43 (1997) 3253-3256. https://doi.org/10.1002/aic.690431213.

[47] D. Sofia, N. Lotrecchiano, D. Cirillo, M. La Villetta, Environmental impact analysis of flue gases emissions for a $20 \mathrm{kwe}$ biomass gasifier, Chem. Eng. Trans. 80 (2020) 295300. https://doi.org/10.3303/CET2080050.

[48] C. Bressot, A. Aubry, C. Pagnoux, O. Aguerre-Chariol, M. Morgeneyer, Assessment of functional nanomaterials in medical applications: can time mend public and occupational health risks related to the products' fate?, J. Toxicol. Environ. Heal. - Part A Curr. Issues. 81 (2018) 957-973. https://doi.org/10.1080/15287394.2018.1477271.

[49] G.I. Do, Magnetron for microwave oven, (1994).

[50] D. Sofia, M. Granese, D. Barletta, M. Poletto, "Laser Sintering of Unimodal Distributed Glass Powders of Different Size," Procedia Eng. 102 (2015) 749-758. https://doi.org/10.1016/j.proeng.2015.01.180.

[51] D.W. Richerson, Modern Ceramic Engineering, CRC Press, 2005. 
https://doi.org/10.1201/b18952.

[52] C.T. Rueden, J. Schindelin, M.C. Hiner, B.E. DeZonia, A.E. Walter, E.T. Arena, K.W. Eliceiri, ImageJ2: ImageJ for the next generation of scientific image data, BMC Bioinformatics. 18 (2017) 529. https://doi.org/10.1186/s12859-017-1934-z.

[53] M. Morgeneyer, L. Brendel, J. Schwedes, Compaction of bidisperse cohesive powders, Granul. Matter. 10 (2008) 295-299. https://doi.org/10.1007/s10035-008-0090-6.

[54] P. García-Triñanes, M. Morgeneyer, J.J. Casares, M. Bao, Use of organic byproducts as binders in the roll compaction of caustic magnesia, Powder Technol. 226 (2012) 173-179. https://doi.org/10.1016/j.powtec.2012.04.039.

[55] P. García-Triñanes, M. Bao, J.J. Casares, T. Ittershagen, M. Morgeneyer, Study on the mechanical strength of primary carbonate tablets, Powder Technol. 204 (2010) 124130. https://doi.org/10.1016/j.powtec.2010.07.027.

[56] A. Franco, M. Lanzetta, L. Romoli, Experimental analvass of selective laser sintering of polyamide powders: An energy perspective, J. Cle n. 1 rod. 18 (2010) 1722-1730. https://doi.org/10.1016/j.jclepro.2010.07.018.

[57] M. Ristic, S.D. Milosevic, M.M. Risti??, S.T\% in.losevi??, Frenkel's theory of sintering, Sci. Sinter. 38 (2006) 7-11. https://dr: ^ry'10.2298/SOS0601007R.

[58] A. Franco, L. Romoli, Characterization of las " energy consumption in sintering of polymer based powders, J. Mater. Prouess. Technol. 212 (2012) 917-926. https://doi.org/10.1016/j.jmatprotec.2011 1'.. 03.

[59] G. Handfield, G.G. Charette, Visc ity and structure of industrial high TiO 2 slags, Can. Metall. Q. 10 (1971) 235-24.4. . .tps://doi.org/10.1179/cmq.1971.10.3.235.

[60] J.N. Israelachvili, Van der Wrals Force-Laws for Bodies of Different Geometries: the Hamaker Constant, in: Intermol . 'rf. Forces, 3rd ed., Elsevier, Academic Press, 2011: pp. 253-289. https://doi.org/19. „ :6/B978-0-12-375182-9.10013-2.

[61] R. Aveyard, S.M. Saleem Inı racial tensions at alkane-aqueous electrolyte interfaces, J. Chem. Soc. Faraday 7 ran 1 Phys. Chem. Condens. Phases. 72 (1976) 1609-1617. https://doi.org/10.1035,'FI,767201609.

[62] J. N. Israelachvili, val. d sr Waals Dispersion Force Contribution to Works of Theory, J. Chem. Soc. Far day Transitions 2. 69 (1973) 1729-1738.

[63] D. Macrì, M. Poi tto, D. Barletta, S. Sutcliffe, P. Lettieri, Analysis of industrial reactive powders ilow properties at high temperature, Powder Technol. 316 (2017) 131-138. https://doi.org/10.1016/j.powtec.2016.10.064.

[64] H. Rumpf, The strength of granules and agglomerates, Wiley, New York, 1962.

[65] I.A. Roberts, C.J. Wang, R. Esterlein, M. Stanford, D.J. Mynors, A three-dimensional finite element analysis of the temperature field during laser melting of metal powders in additive layer manufacturing, Int. J. Mach. Tools Manuf. (2009). https://doi.org/10.1016/j.ijmachtools.2009.07.004. 
Figure 1 - Macro photographs of 10x10 mm sintered artefacts. Letters A to B refer to the powder samples in Table 1 differing for the mean particle size. The sintering process was carried out with a $10 \mathrm{~W}$ laser beam and with $50 \mathrm{~mm} \mathrm{~s}^{-1}, 100 \mathrm{~mm} \mathrm{~s}^{-1}, 150 \mathrm{~mm} \mathrm{~s}^{-1}$ of laser scanning speed changing along the columns.

Figure 2 - First column on the left: microphotographs of original titanium dioxide powders. Columns on the right: microphotographs of $10 \times 10 \mathrm{~mm}$ sintered artefacts. Letters A to B refer to the powder samples in Table 1 differing for the mean part iv's size. The sintering process was carried out with a $10 \mathrm{~W}$ laser beam and with $50 \mathrm{~mm},{ }^{-1}, .00 \mathrm{~mm} \mathrm{~s}^{-1}, 150 \mathrm{~mm} \mathrm{~s}^{-1}$ of laser scanning speed from left to right.

Figure 3 - Artefact properties vs the nominal : artıcle size of the powder samples: a) mass, b) thickness properties, c) Depth Rise, d) ten. ,e strength. 10x10 mm sintered artefacts produced with a laser beam of $10 \mathrm{~W}$ and a laser $\mathrm{cc}^{\mathrm{a}} \cdot$ nning speed of $50 \mathrm{~mm} \mathrm{~s}-1$.

Figure 4 - Schematic of the eff $r$ vf the laser beam hitting a bed of powders

Figure 5 - (A) Comp ${ }^{\text {ris }}$ `n oetween the experimental and the predicted values of the solid interparticle neck dimensions for different sizes of initial particles. (B) - (C) Sensitivity analysis on the sintered neck size as a function of the radius of curvature. 
Table 1. Particle size distribution and sintering temperature of the five sieved samples tested.

\begin{tabular}{ccccc}
\hline Ref & Original cut size, $\boldsymbol{\mu m}$ & Sieving range, $\boldsymbol{\mu m}$ & $\boldsymbol{d}_{\boldsymbol{p}}, \boldsymbol{\mu \mathbf { m }}$ & $\boldsymbol{T s}_{\boldsymbol{s}}{ }^{\circ} \mathbf{C}$ \\
\hline $\mathbf{A}$ & $<50$ & $26-32$ & 28 & 1080 \\
$\mathbf{B}$ & $10-100$ & $53-63$ & 58 & 1270 \\
$\mathbf{C}$ & $10-200$ & $106-125$ & 116 & 1290 \\
$\mathbf{D}$ & $100-200$ & $150-200$ & 180 & 1340 \\
$\mathbf{E}$ & $>200$ & $212-250$ & 245 & 1360 \\
\hline
\end{tabular}




\section{HIGHLIGHTS}

- Selective laser sintering was applied to fabricate semi-3D ceramic specimens

- Optical and mechanical tests were performed to analyse the resulting properties

- Literature models were used as comparative tools for the results obtained

- A sensitivity analysis of the models' parameters is performed 


\section{CRediT author statement}

Daniele Sofia: Conceptualization, Methodology, Formal analysis, Investigation, Writing Original Draft. Domenico Macrì: Formal analysis, Investigation, Writing - Original Draft, Writing - Review \& Editing, Data Curation. Diego Barletta: Conceptualization, Visualization, Supervision. Paola Lettieri: Supervision. Massimo Poletto: Conceptualization, Visualization, Supervision, Writing - Review \& Editing, Project administration. 


\section{Declaration of interests}

$\bigotimes$ The authors declare that they have no known competing financial interests or personal relationships that could have appeared to influence the work reported in this paper.

$\square$ The authors declare the following financial interests/personal relationships which may be considered as potential competing interests: 

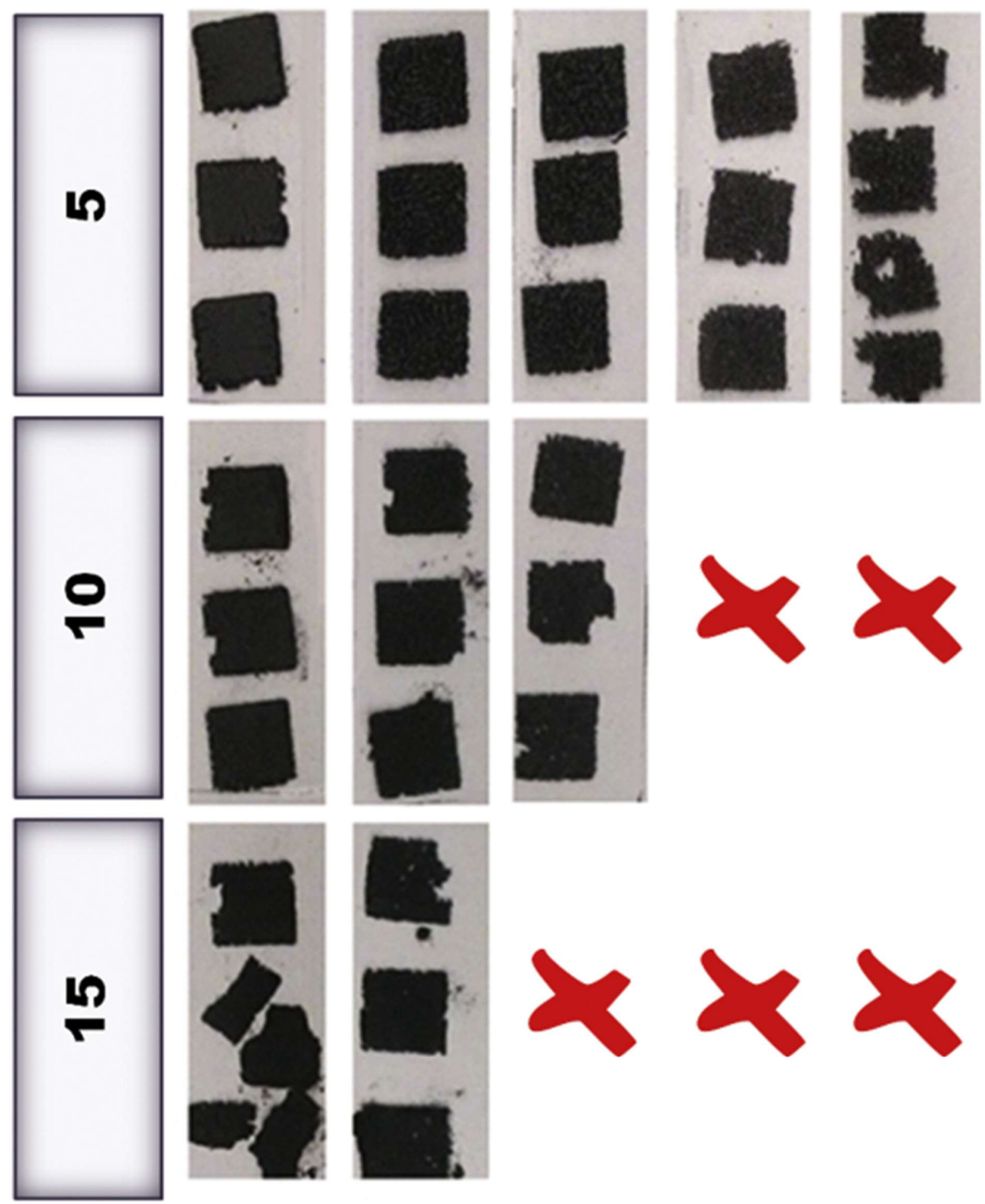

거에
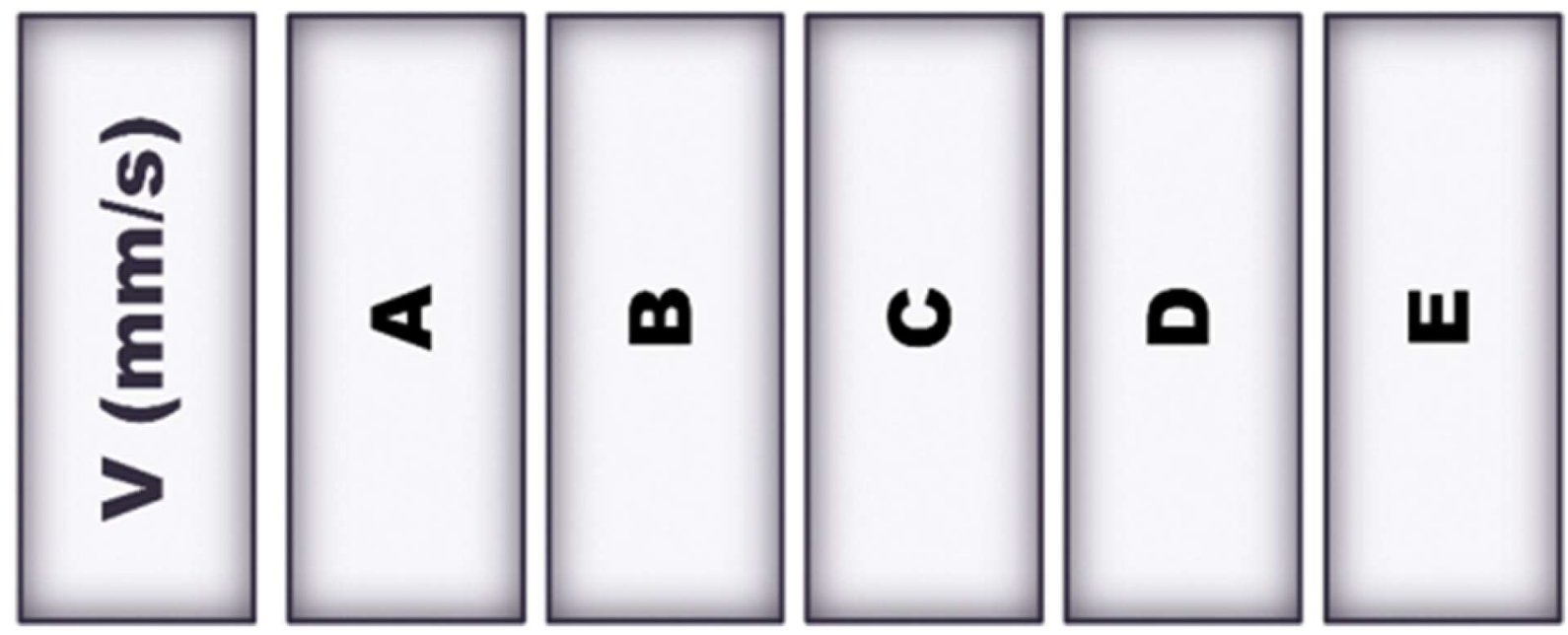

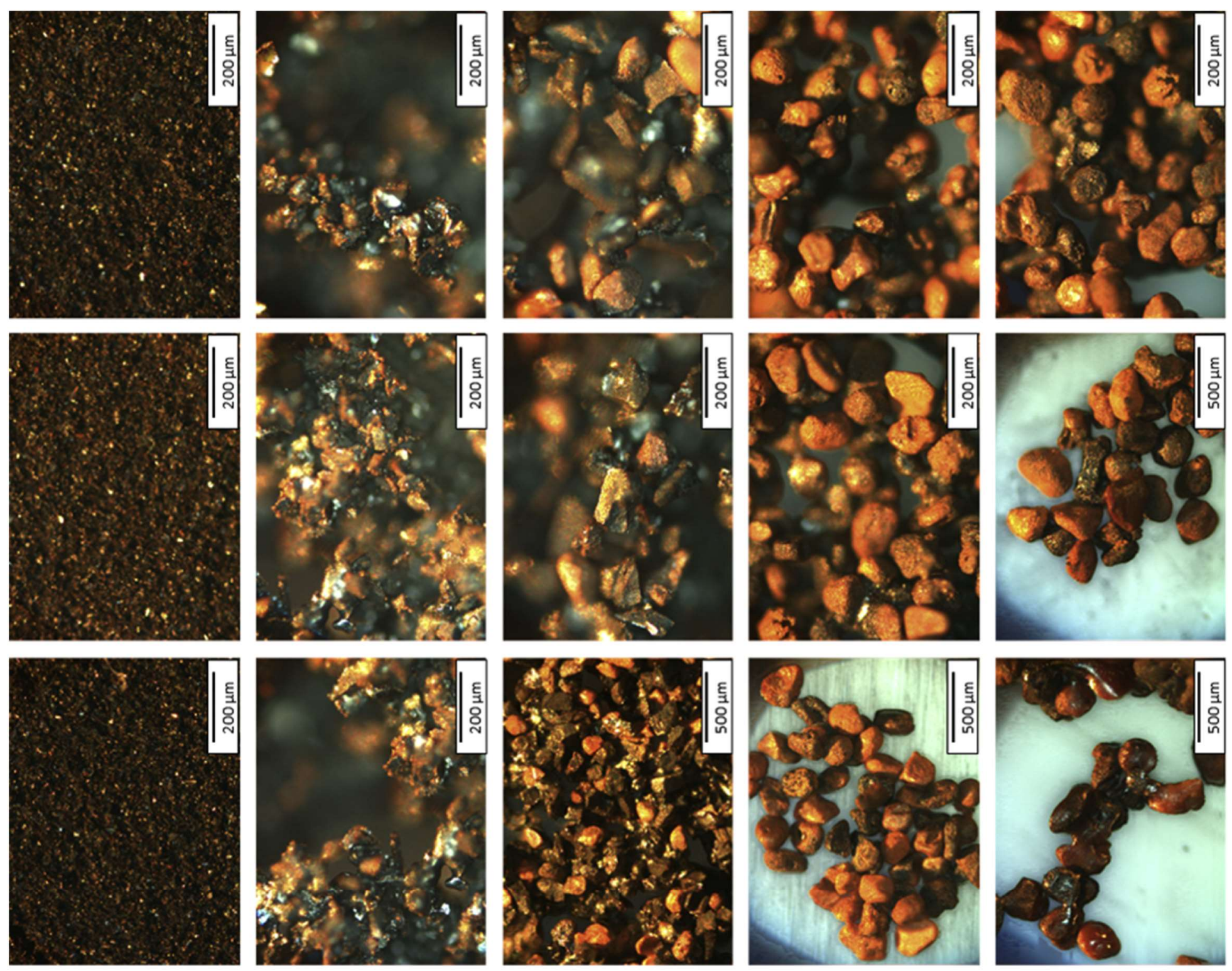

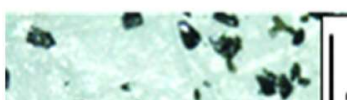

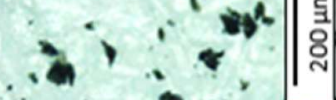

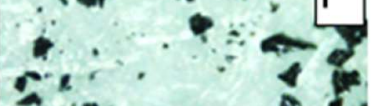

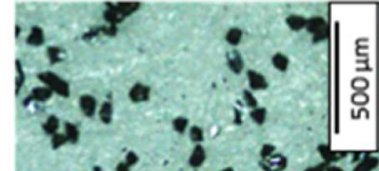
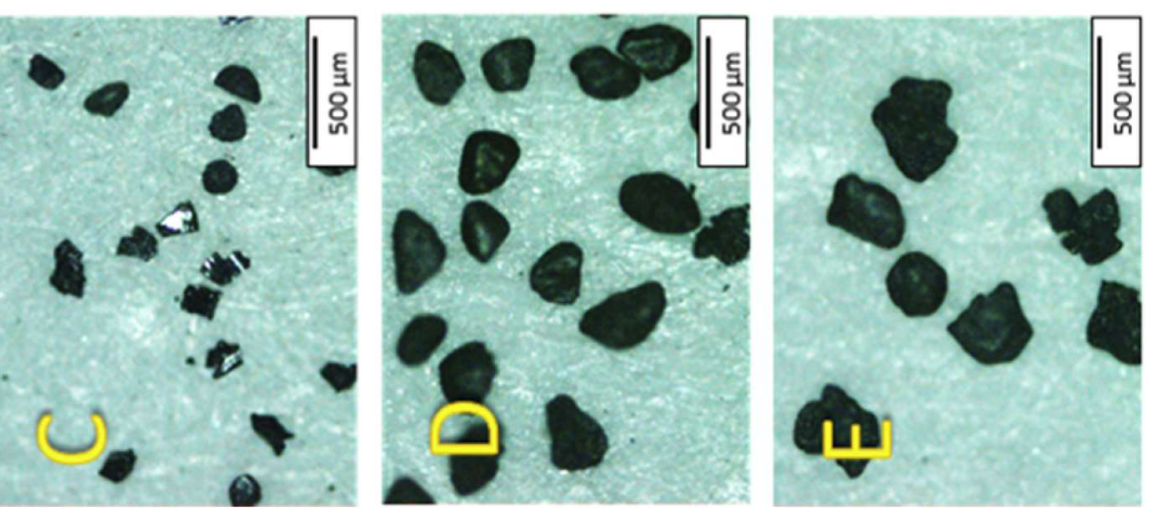

N
$\frac{1}{5}$
$\frac{00}{4}$ 

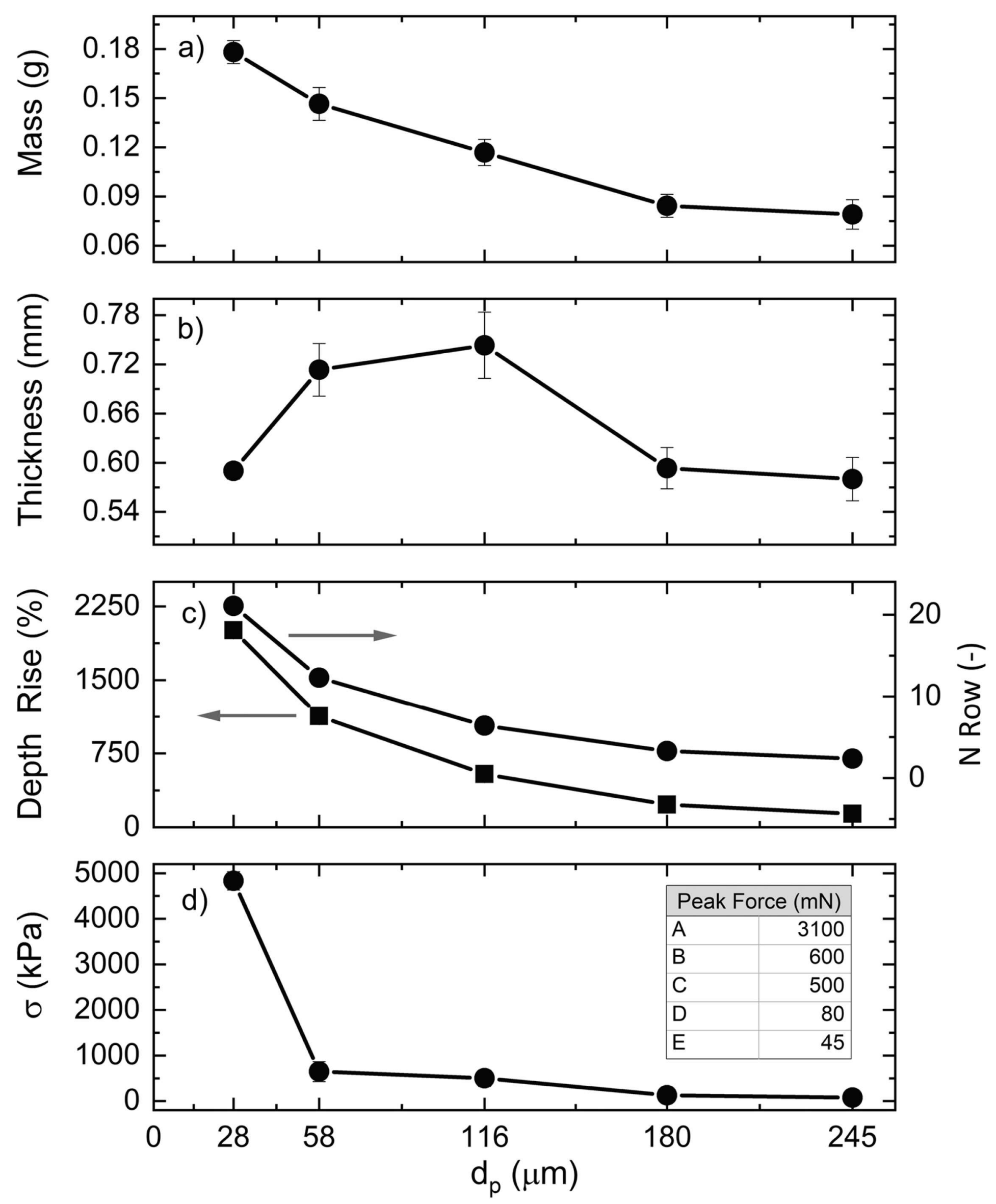

Figure 3 

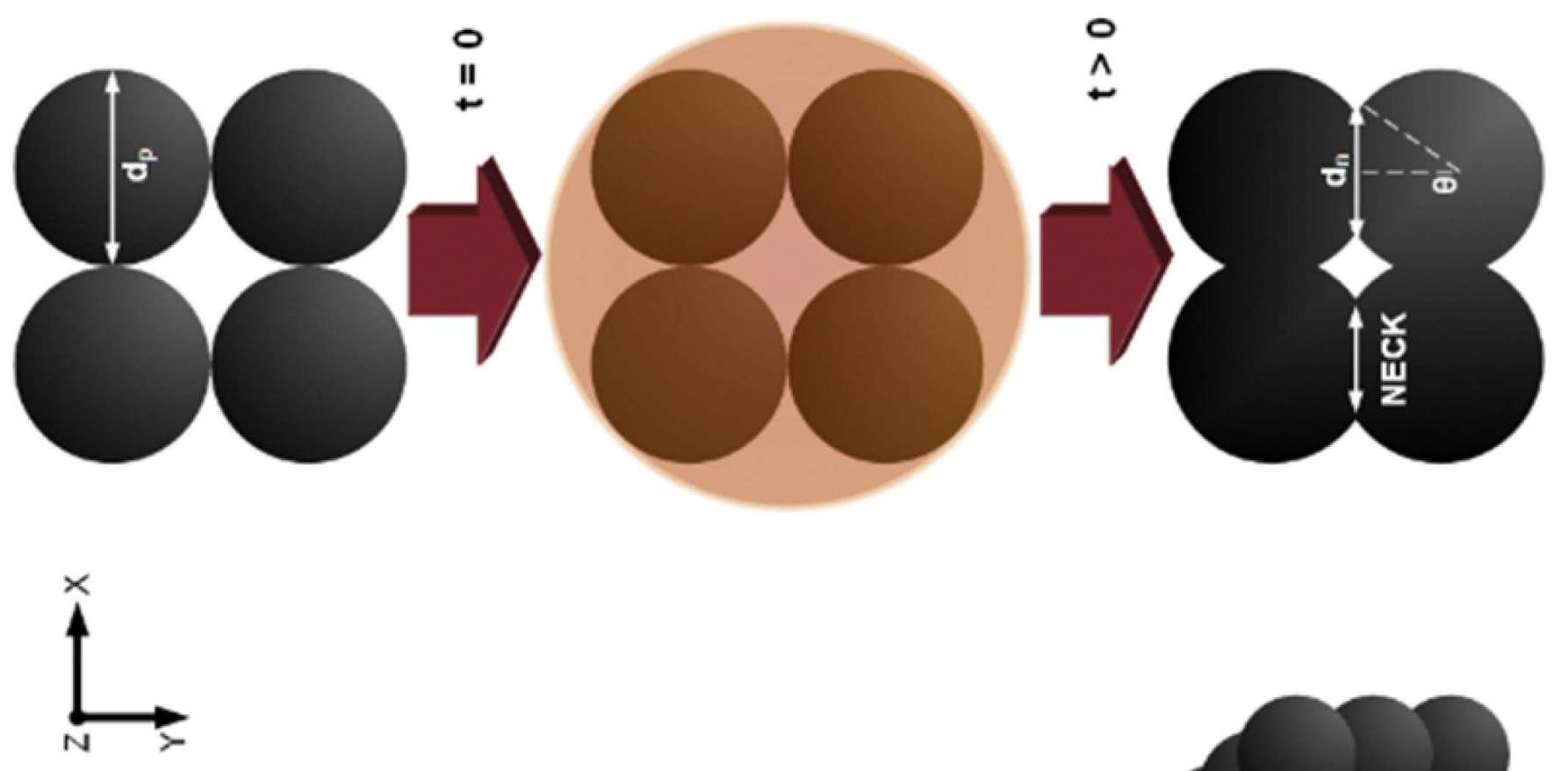

$\nabla$
늠
한

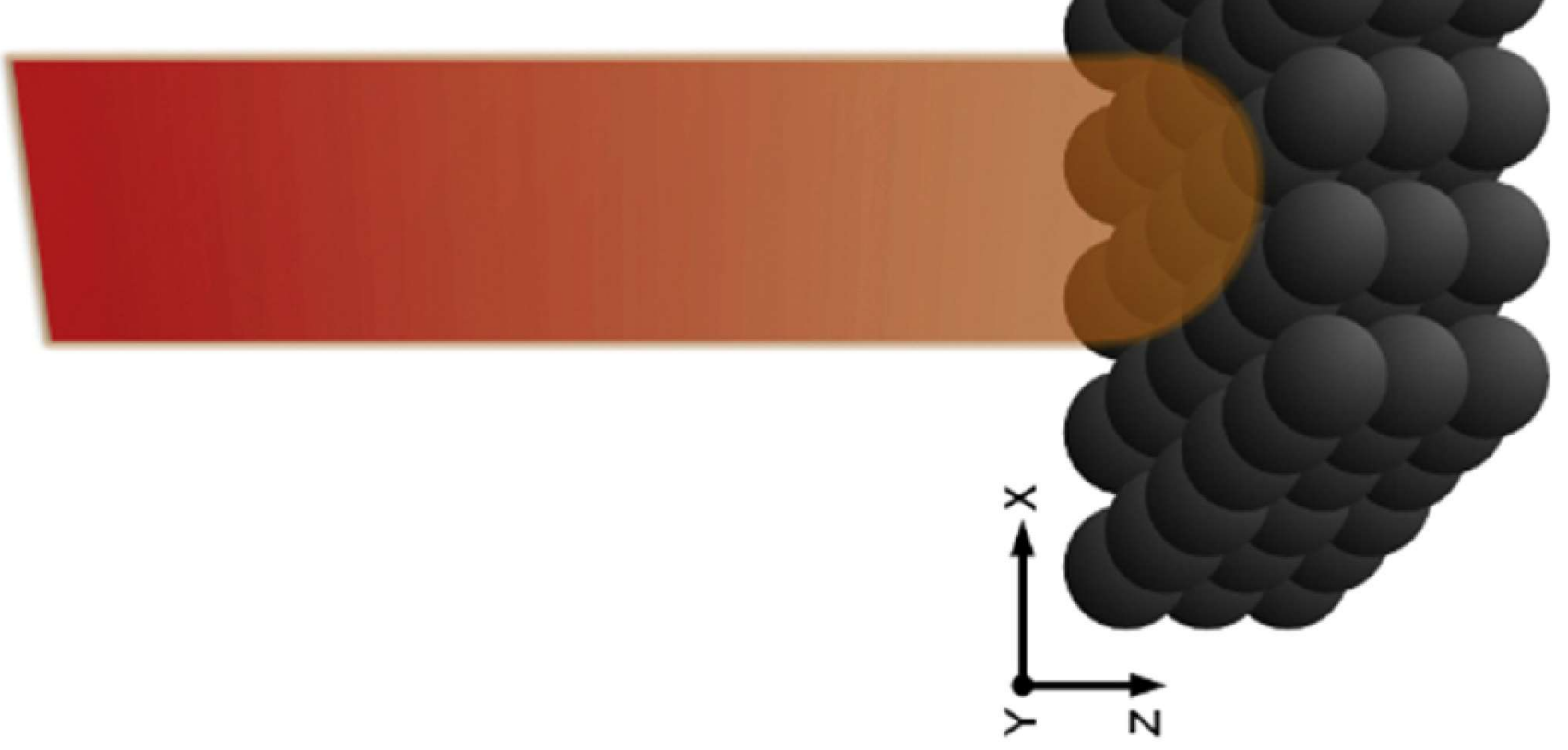


(A)

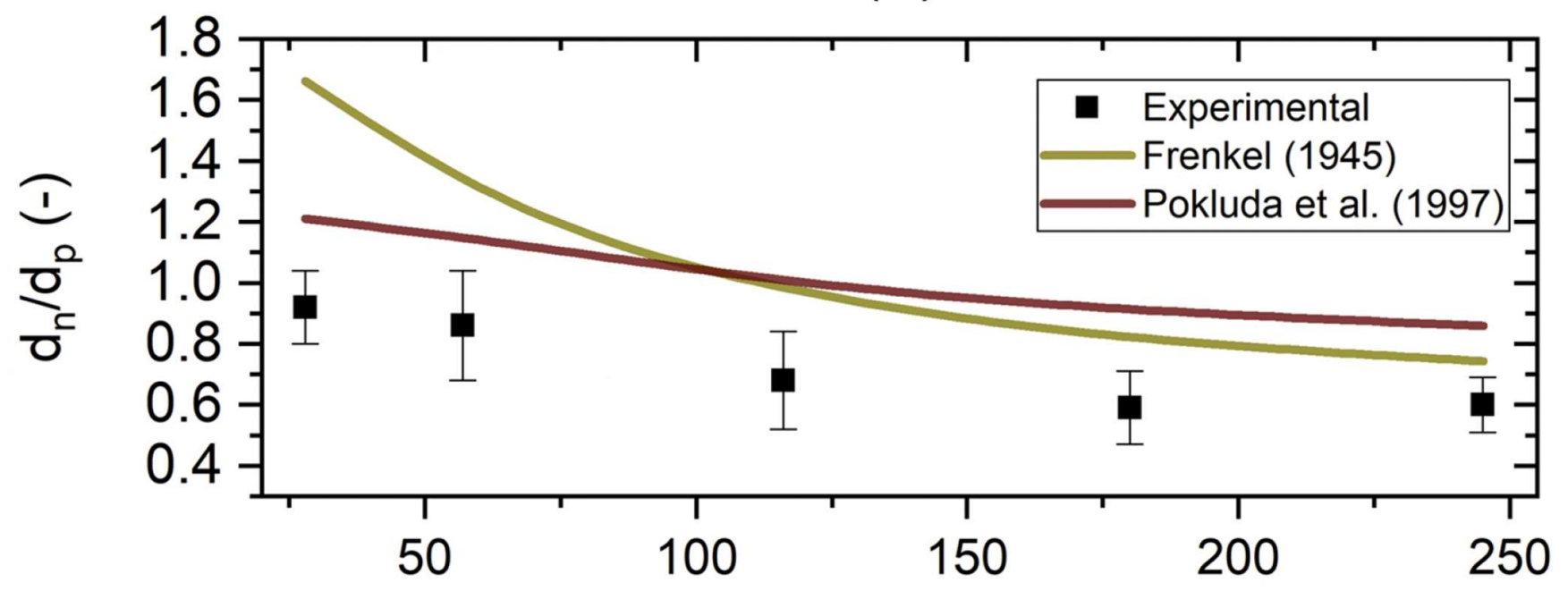

(B) Sensitivity on Frenkel (1945) model

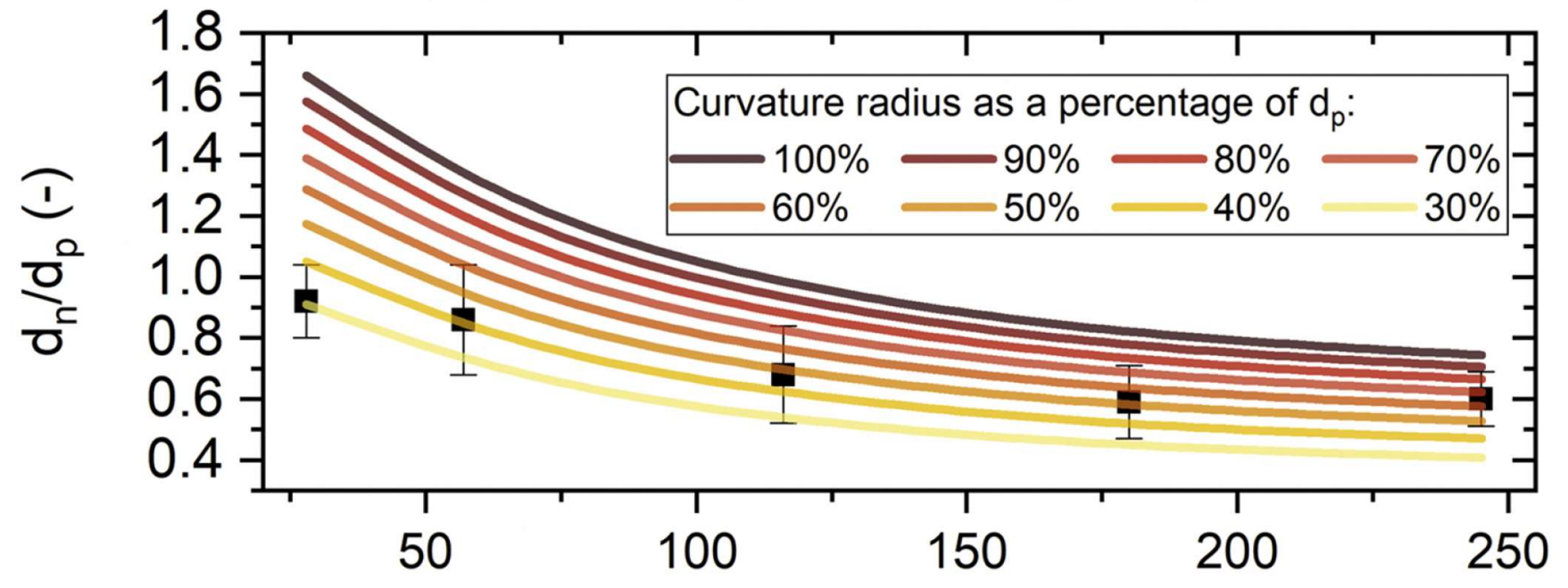

(C) Sensitivity on Pokluda et al. (1997) model

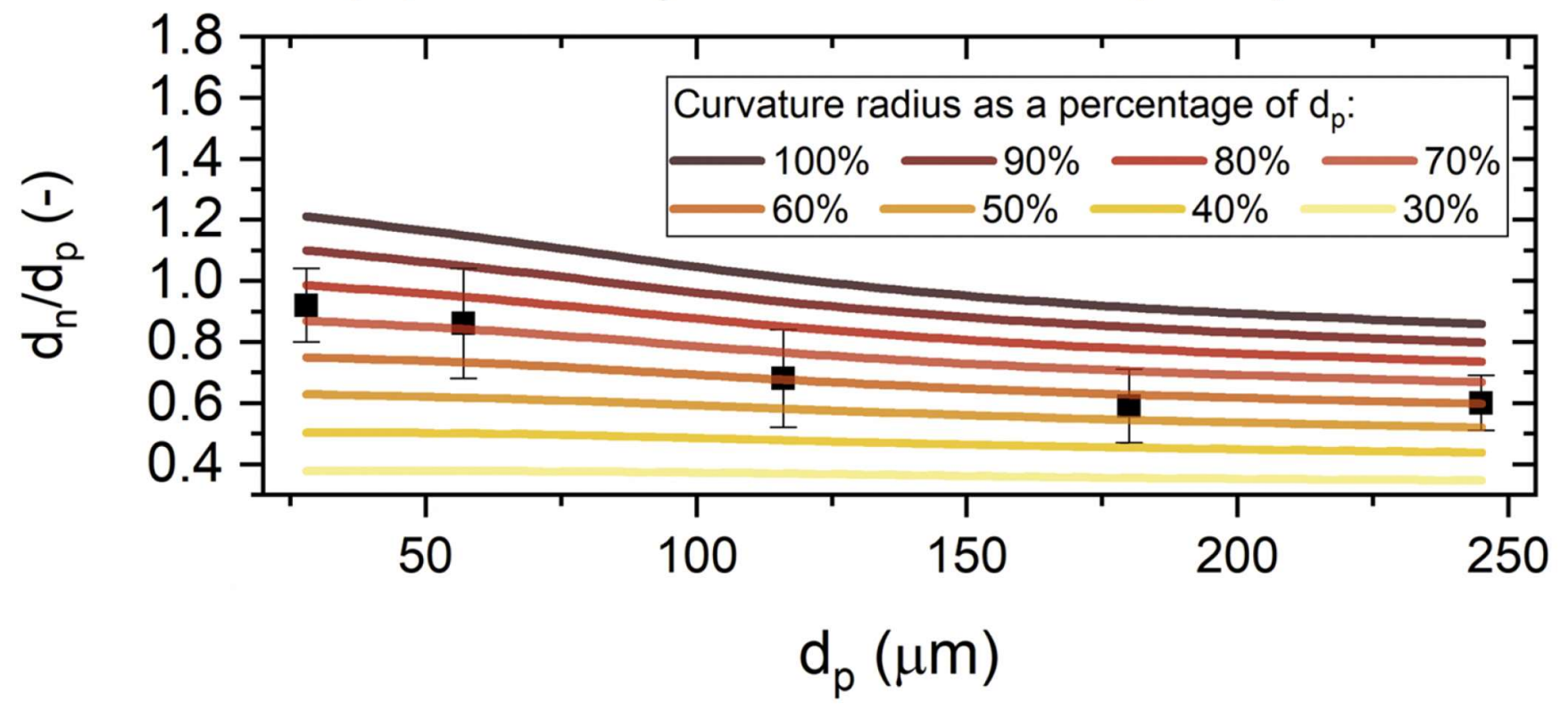

Figure 5 